\title{
Determinants of Diabetic Foot Ulcer Among Adult Patients with Diabetes Attending the Diabetic Clinic in Tikur Anbessa Specialized Hospital, Addis Ababa, Ethiopia: Unmatched Case-Control Study
}

This article was published in the following Dove Press journal: Diabetes, Metabolic Syndrome and Obesity: Targets and Therapy

\author{
Guesh Teklu Woldemariam, (1D) \\ Niguse Tadele Atnafu, (iD) ${ }^{2}$ \\ Yosief Tsige Radie, ${ }^{2}$ \\ Getahun Tarekegn Wolde, (1D) ${ }^{3}$ \\ Teklehaimanot Tesfay \\ Gebreagziabher, (D) \\ Tesfay Gebreslassie \\ Gebrehiwot, (1D) \\ Yared Haileselassie Teka,' Milete \\ Gebrehiwot Hagos, ' \\ Haftamu Mamo Hagezom, (ID) ${ }^{4}$ \\ Hailu Belay Yigzaw, ${ }^{4}$ \\ Haftom Tesfay Gebremedhin, (D) ${ }^{4}$ \\ Hagos Mehari Mezgebo, ${ }^{4}$ \\ Alem Gebremariam, (D) ${ }^{5}$ \\ 'Department of Nursing, College of \\ Medicine and Health Sciences, Adigrat \\ University, Tigrai, Ethiopia; ${ }^{2}$ School of \\ Nursing and Midwifery, College of Health \\ Sciences, Addis Ababa University, Addis \\ Ababa, Ethiopia; ${ }^{3}$ Tikur Anbessa Specialized \\ Hospital, Addis Ababa University, Addis \\ Ababa, Ethiopia; ${ }^{4}$ Department of Psychiatry, \\ College of Medicine and Health Sciences, \\ Adigrat University, Tigrai, Ethiopia; \\ ${ }^{5}$ Department of Public Health, College of \\ Medicine and Health Sciences, Adigrat \\ University, Tigrai, Ethiopia
}

Correspondence: Guesh Teklu Woldemariam

Department of Nursing, College of

Medicine and Health Sciences, Adigrat

University, Postal Address: 50, Tigrai,

Ethiopia

Tel +251940304I40

Email gueshomt2I@gmail.com
Background: Diabetic foot ulcer is among the commonest complications of diabetic mellitus attributed to a number of morbidity and mortality cases in diabetic patients. Nowadays, the incidence of diabetic foot ulcer is increasing due to the increased prevalence of diabetes. However, the risk factors of the problem are less studied in Ethiopia. Hence, this study was conducted to assess the determinants of diabetic foot ulcer among adult patients with diabetes attending a diabetic clinic in Tikur Anbessa Specialized Hospital, Addis Ababa, Ethiopia in 2019.

Patients and Methods: An institution-based unmatched case-control study was conducted on 161 patients with diabetes (53 patients with diabetes with foot ulcer and 108 patients with diabetes without foot ulcer). Cases were selected from patients with diabetes with foot ulcer by consecutive sampling technique and controls from patients with diabetes without diabetic foot ulcer by systematic random sampling technique. A binary logistic regression model was used to assess the association between the dependent and independent variables. All variables with a $P$-value $<0.25$ were included in the multivariable analysis. Statistical significance was declared at $P$-value $<0.05$ with $95 \%$ confidence interval.

Results: In this study, 28 (52.8\%) cases and 55 (50.9\%) controls were male. Taking insulin alone $(\mathrm{AOR}=2.75,95 \% \mathrm{CI}=1.04-7.23)$, having peripheral neuropathy $(\mathrm{AOR}=7.56,95 \%$ $\mathrm{CI}=2.82-20.24)$, not inspecting feet daily ( $\mathrm{AOR}=5.61,95 \% \mathrm{CI}=2.24-14.05)$, and using moisturizing cream between toes $(\mathrm{AOR}=3.35,95 \% \mathrm{CI}=1.35-8.32)$ were positively associated with diabetic foot ulcer, whereas employed $(\mathrm{AOR}=0.35,95 \% \mathrm{CI}=0.14-0.87)$ and combined treatment (insulin and oral hypoglycemic agents) $(\mathrm{AOR}=0.11,95 \% \mathrm{CI}=0.02-0.57)$ were negatively associated with diabetic foot ulcer.

Conclusion: Diabetic foot ulcer was significantly associated with occupation, kind of treatment of diabetes mellitus taking, peripheral neuropathy, inspecting feet daily, and putting moisturizing cream between toes. It will be helpful if diabetic patients inspect their feet on a daily basis and do not put moisturizing cream between their toes.

Keywords: diabetic foot ulcer, determinants, Ethiopia

\section{Background}

Diabetes mellitus causes macro-vascular and micro-vascular complications. Diabetic foot ulcer (DFU) is among the long-term micro-vascular complications of diabetic 
mellitus that have a lifetime risk between $19-34 \%$, though many of the occurrences could be prevented. ${ }^{1,2}$

Diabetic foot ulcer is among the overwhelming complications of diabetic mellitus and causes diabetes related foot deformities as a result of the ulcers. ${ }^{3}$

Though diabetic foot ulcer can be prevented by a multidisciplinary health professional's approach, it is important to teach and instruct diabetic patients to protect their feet by wearing properly fitting footwear, not to walk barefoot or in socks only, whether at home or when outside. They should also be taught and instructed to inspect their feet and the inner side of their shoes, wash their feet (with careful drying, particularly between the toes) on a daily basis, and use emollients to lubricate dry skin for a better outcome. ${ }^{4}$

The global prevalence of diabetic foot ulcers was $6.3 \%$, which was higher in men and in type 2 patients with diabetes. The prevalence of diabetic foot ulcer in Africa was $7.2 \% .^{5}$ The prevalence of diabetic foot ulcer was $18.1 \%$ among patients with type 2 diabetes mellitus on treatment in Khartoum, Sudan. ${ }^{6}$ According to the studies conducted in different regions of Ethiopia, the prevalence of diabetic foot ulcer was: $14.8 \%, 13.6 \%$, $12 \%$, and $4.4 \%$ in Arbamich, Gondar, Mekelle, and Dessie, respectively. ${ }^{7-10}$

DFU is the major cause of lower extremity amputations in diabetic patients. Every 30 seconds a lower limb or part of a lower limb is lost to amputation somewhere in the world as a consequence of diabetes. ${ }^{11}$ The study conducted in Turkey revealed that $41.4 \%$ of diabetic patients with DFU underwent an amputation. ${ }^{12}$ Moreover, DFU accelerates the mortality rate among diabetic patients, as shown by the retrospective cohort study conducted in Saudi Arabia stating deceased patients increased by almost 2-fold in diabetic patients with foot ulcers compared to diabetic patients without foot ulcers. ${ }^{13}$

Similarly, a study from the UK also revealed a higher rate of mortality among DM patients with DFU compared to those without DFU. Among the diabetic patients who developed new onset foot ulcer, $8.1 \%$ died within 12 months of their DFU follow-up, and the 5-year death rate for people with diabetic foot ulcer was $42.2 \%{ }^{14}$

Several factors have contributed to the development of DFU. These include foot deformity, prior amputation, trauma, peripheral arterial disease, peripheral neuropathy, hypertension, duration of diabetes mellitus for greater than 10 years, male gender, age greater than 45 years old, non-noticeable repetitive trauma, and longer duration of past foot ulcers. These were significant factors for the development of DFU. ${ }^{15-17}$

Several studies have attempted to identify risk factors for DFU but did not assess the status of putting moisturizing cream between toes, family support during foot care, and physical activity (exercise) status of the individual as possible risk factors for the development of DFU. ${ }^{6-9}$ Therefore, this study was conducted to determine the effect of these variables on diabetic foot ulcers.

\section{Patients and Methods}

\section{Study Design, Setting, and Period}

This institution-based unmatched case control study was conducted in Tikur Anbessa Specialized Hospital (TASH), Addis Ababa, which is the capital city of Ethiopia, from March 27-May 13, 2019.

\section{Study Participants}

All patients with diabetes attending the diabetic clinic in TASH were the source population and cases (patients with diabetes who developed diabetic foot ulcer that was diagnosed by a physician), and controls (patients with diabetes who did not develop diabetic foot ulcer) who were attending the diabetic clinic in TASH during the study period were the study population. Patients with diabetes who had a traumatic ulcer due to a car accident or any injury and those who were severely ill and unable to communicate were excluded.

\section{Sample Size and Sampling Technique}

Sample size was determined by using Epi Info Version 7 statistical software to determine two population proportions by using $95 \% \mathrm{CI}$, power $80 \%$, control to case ratio $2, \mathrm{OR}=3$, which is the ratio of odds of dry skin among patients with diabetes with DFU to odds of dry skin among patients with diabetes without DFU, the probability of exposure to dry skin among patients with diabetes without $\mathrm{DFU}=19.6 \%$, and the probability of exposure to dry skin among patients with diabetes with DFU $=43.3 \%{ }^{18}$ The calculated sample size was 147 (49 cases and 98 controls). By adding a $10 \%$ non-response rate, the total sample size was 162 (54 cases and 108 controls).

Controls were selected from patients with diabetes without diabetic foot ulcer using a systematic random sampling technique. The sampling interval or constant number $\mathrm{K}$ was nine. It was obtained by dividing the total number of patients with diabetes without DFU that are receiving care during the study 
period $(\mathrm{N})$ to the calculated sample size of the patients with diabetes without DFU (n). Therefore, $\mathrm{K}$ was calculated by the formula, $\mathrm{K}=\mathrm{N} / \mathrm{n}$. The first control was selected using lottery method as a starting point, and it was the 5 th participant. Then the patients with diabetes without DFU were selected by taking the 9th participant until the predetermined sample size was obtained. Cases were selected from patients with diabetes with foot ulcer using consecutive sampling technique until the predetermined sample size was obtained.

\section{Data Collection Tools and Procedures}

Structured questionnaire adapted from different similar literature, ${ }^{7-9,18-20}$ and standard evaluation tools for diabetic foot ulcers ${ }^{21-24}$ were used to collect data. An intervieweradministered structured questionnaire and medical chart reviewing were carried out to collect data from the cases and controls. In addition to this, patients were also physically examined to assess for the presence of any deformities.

\section{Data Quality Assurance}

The questionnaire was first prepared in English and, to assure the data quality, the English version of the questionnaire was translated into Amharic language, the official language of the study area, by an expert fluent in the language. It was then translated back into English by another person to ensure consistency with the English language questionnaire. The Amharic language questionnaire was used to collect data.

A pilot study was done 2 weeks before the actual data collection time on $5 \%$ (eight patients with diabetes) of the calculated sample size in St. Paul's Hospital Millennium Medical College. Ambiguous words and concepts were corrected accordingly.

One day of training was given for data collectors and supervisors about the overall data collection process. Three MSc graduate students collected the data. One MSc holder supervised the overall data collection process. Participants' details were remaining anonymous and confidentiality was guaranteed. The information in the study tool was checked for completeness before entering into SPSS.

\section{Data Analysis Procedure}

Data were checked, coded, and entered to Epi-Data Manager version 4.4.2.2, and were exported to SPSS version 24 for analysis.

Descriptive statistics such as frequencies, percentages, means, standard deviations, and crosstabs were computed to describe the study population in relation to relevant variables (sex, age, marital status, educational level, occupation, residence, and other variables). Model fitness was checked using Hosmer-Lemeshow goodness-of-fit. Bivariate logistic regression was used to assess the association between independent variables and dependent variable at a $P<0.25$ significance level. Those significant variables in the bivariate logistic regression were selected to multivariable logistic regression analysis to determine the association between a set of independent variables with the dependent variable using a step wise backward conditional method. ${ }^{25}$ The magnitude of the association was measured by using an Odds Ratio with its $95 \%$ confidence interval. Statistical significance was declared at $P<0.05$. Finally, the data were presented with texts and tables.

\section{Operational Definitions Case (Patient with Diabetes with Diabetic Foot Ulcer)}

This was a patient with diabetes who was diagnosed as having foot ulcer which was identified from the patient's medical card (presence of foot ulcer was judged from the patient's medical record).

\section{Control (Patient with Diabetes without Diabetic Foot Ulcer)}

This was a patient with diabetes who was not diagnosed as having foot ulcer which was identified from the patient's medical card.

\section{Foot Deformity}

When the big toe of the patients with diabetes was turned toward the second toe and the base of the big toe was pushed to the side, and if the tip of the toe was bent.

\section{Well Fit Footwear}

Footwear that was wider than the size of the foot. That was checked by measuring the size of the foot on paper with a marker and that of a shoe. Then both the size of the foot and shoe were compared, along with no reddened areas on the foot on removal of the footwear

\section{Fit Footwear}

When footwear was equal to the size of the foot and there were reddened areas on the foot on removal of the footwear.

\section{Callus}

Patients with diabetes were observed and palpated for the presence of thick areas on the bottom or sides of the feet and toes. 


\section{Dry Skin}

Patients with diabetes were observed and palpated for rough skin.

\section{Nail Deformity}

Patients with diabetes were observed for ingrown toenails or thickened nail fold skin.

\section{Regular Physical Exercise}

Patients with diabetes were asked if they perform physical exercise, which could be either walking, jogging, or running three times per week that lasts 30 minutes or more.

\section{Body Mass Index (BMI)}

This is defined as the weight in kilograms divided by the square of the height in meters $\left(\mathrm{kg} / \mathrm{m}^{2}\right)$. It is classified as a BMI less than $18.5 \mathrm{~kg} / \mathrm{m}^{2}=$ underweight, BMI ranging from $18.5-24.9 \mathrm{~kg} / \mathrm{m}^{2}=$ normal range, BMI ranging from $25-29.9 \mathrm{~kg} / \mathrm{m}^{2}=$ overweight, and BMI $\geq 30 \mathrm{~kg} / \mathrm{m}^{2}=$ obese $^{26}$

\section{Ethics Approval and Consent to Participate}

An ethical clearance letter was obtained from the institutional review board of Addis Ababa University, College of Health Sciences, School of Nursing and Midwifery research committee with a protocol number of 021/19/SNM. An official letter was submitted to Tikur Anbessa Specialized Hospital, diabetic clinic, and then permission was obtained from the concerned bodies. All participants were informed about the purpose of the study, and this study was conducted in accordance with the Declaration of Helsinki. Prior to data collection, information was given to the participants and participants' voluntary participation, confidentiality, anonymity, and freedom to withdraw from the study at any time were assured and their participation had no impact on the care that they get from the hospital. As a result, consents were obtained from the participants. Finally, written informed consent was obtained from all the study participants.

\section{Results}

\section{Socio-Demographic Characteristics of Respondents}

A total of 161 patients with diabetes, 53 cases and 108 controls, participated in the study, with a response rate of $99.4 \%$.

The mean age \pm standard deviation (SD) of the cases and controls was $50.55 \pm 6.34$ years and $51.48 \pm 16.62$ years, respectively. Among the respondents, 28 (52.8\%) cases and 55 (50.9\%) controls were males (Table 1).

\section{Clinical Characteristics of Respondents}

The number of type I DM among the cases and controls was $16(30.2 \%)$ and $30(27.8 \%)$, respectively. The number of cases and controls having DM for less than 10 years was $20(37.7 \%)$ and $49(45.4 \%)$, respectively. In addition, the mean $\pm \mathrm{SD}$ year duration of $\mathrm{DM}$ among cases and controls was 13.04 \pm 8.44 and 12.47 \pm 9.47 , respectively. The proportion of hypertension among the cases and controls was $20(37.7 \%)$ and $38(35.2 \%)$, respectively.

The number of cases and controls having foot deformity was seven $(13.2 \%)$ and six $(5.6 \%)$, respectively. The proportion of kidney disease among cases and controls was two (3.8\%) and eight (7.4\%), respectively (Table 2$)$.

The proportion of callus among cases and controls was $11(20.8 \%)$ and $14(13.0 \%)$, respectively. The proportion of dry skin among cases and controls was five (9.4\%) and $12(11.1 \%)$, respectively.

Table I Socio-Demographic Characteristics of Diabetic Patients in Addis Ababa City, $2019(n=161)$

\begin{tabular}{|l|l|l|}
\hline Variables & Cases (\%) & Controls (\%) \\
\hline Age category in years & & \\
I8-27 & $6(28.6)$ & $15(71.4)$ \\
$28-37$ & $9(45.0)$ & $11(55.0)$ \\
$38-47$ & $4(30.8)$ & $9(69.2)$ \\
$48-57$ & $12(32.4)$ & $25(67.6)$ \\
$58-67$ & $15(34.1)$ & $29(65.9)$ \\
$\geq 68$ & $7(26.9)$ & $19(73.1)$ \\
\hline Marital status & & \\
Married & $40(35.7)$ & $72(64.3)$ \\
Single & $8(22.9)$ & $27(77.1)$ \\
Divorced & $5(35.7)$ & $9(64.3)$ \\
\hline Educational level & & \\
No formal education & $4(25.0)$ & $12(75.0)$ \\
Primary & $15(36.6)$ & $26(63.4)$ \\
Secondary & $7(36.8)$ & $12(63.2)$ \\
Above secondary & $27(31.8)$ & $58(68.2)$ \\
\hline Occupation & & \\
Employed & $30(40.0)$ & $45(60.0)$ \\
Unemployed & $23(26.7)$ & $63(73.3)$ \\
\hline Residence & & $105(67.7)$ \\
Urban & $50(32.3)$ & $3(50.0)$ \\
Rural & $3(50.0)$ & \\
\hline
\end{tabular}


Table 2 Clinical Factors of Diabetic Patients in Addis Ababa City, $2019(n=161)$

\begin{tabular}{|c|c|c|}
\hline Variables & Cases (\%) & Controls (\%) \\
\hline $\begin{array}{l}\text { Regularly visit a physician } \\
\text { Yes } \\
\text { No }\end{array}$ & $\begin{array}{l}53(33.1) \\
0(0.0)\end{array}$ & $\begin{array}{l}107(66.9) \\
I(100.0)\end{array}$ \\
\hline $\begin{array}{l}\text { Treatment kind of DM } \\
\text { Oral hypoglycemic agents } \\
\text { Insulin } \\
\text { Both }\end{array}$ & $\begin{array}{l}15(30.0) \\
35(45.5) \\
3(8.8)\end{array}$ & $\begin{array}{l}35(70.0) \\
42(54.5) \\
31(91.2)\end{array}$ \\
\hline $\begin{array}{l}\text { Heart disease } \\
\text { Yes } \\
\text { No }\end{array}$ & $\begin{array}{l}10(34.5) \\
43(32.6)\end{array}$ & $\begin{array}{l}19(65.5) \\
89(67.4)\end{array}$ \\
\hline $\begin{array}{l}\text { Peripheral neuropathy } \\
\text { Yes } \\
\text { No }\end{array}$ & $\begin{array}{l}25(56.8) \\
28(23.9)\end{array}$ & $\begin{array}{l}19(43.2) \\
89(76.1)\end{array}$ \\
\hline $\begin{array}{l}\text { Dyslipidemia } \\
\text { Yes } \\
\text { No }\end{array}$ & $\begin{array}{l}0(0.0) \\
53(33.9)\end{array}$ & $\begin{array}{l}9(100.0) \\
99(65.1)\end{array}$ \\
\hline $\begin{array}{l}10 \text { g- monofilament } \\
\text { Positive } \\
\text { Negative }\end{array}$ & $\begin{array}{l}24(46.2) \\
29(26.6)\end{array}$ & $\begin{array}{l}28(53.8) \\
80(73.8)\end{array}$ \\
\hline $\begin{array}{l}\text { Nail problems } \\
\text { Nail deformity } \\
\text { No nail problems }\end{array}$ & $\begin{array}{l}14(53.8) \\
39(28.9)\end{array}$ & $\begin{array}{l}12(46.2) \\
96(7 I .1)\end{array}$ \\
\hline $\begin{array}{l}\text { BMI } \\
\qquad \begin{array}{l}<18.5 \\
18.5-24.9 \\
25-29.9 \\
\geq 30\end{array}\end{array}$ & $\begin{array}{l}11(73.3) \\
5(11.9) \\
19(31.1) \\
18(43.2)\end{array}$ & $\begin{array}{l}4(26.7) \\
37(88.1) \\
42(68.9) \\
25(58.1)\end{array}$ \\
\hline
\end{tabular}

\section{Behavioral Factors of Respondents}

The proportion of feet washing on a daily basis among the cases and controls was $50(94.3 \%)$ and 99 (91.7\%), respectively. The proportion of inspecting feet entirely among the cases and controls was $31(58.5 \%)$ and $57(52.8 \%)$, respectively. The proportion of getting family assistance during foot inspection among cases and controls was $13(24.5 \%)$ and $24(22.2 \%)$, respectively. The proportion of reading handouts on proper footwear among cases and controls was 18 (34.0\%) and $31(28.7 \%)$. respectively, and the proportion of attending classes on foot care among cases and controls was $24(45.3 \%)$ and $53(49.1 \%)$, respectively. The proportion of inspecting shoes for foreign objects or torn linings among cases and controls was 37 (69.8\%) and
Table 3 Behavioral Factors of Diabetic Patients in Addis Ababa City, $2019(n=161)$

\begin{tabular}{|c|c|c|}
\hline Variables & Cases (\%) & Controls (\%) \\
\hline \multicolumn{3}{|c|}{ Ever wear shoes without socks } \\
\hline Yes & $20(28.6)$ & 50 (7I.4) \\
\hline No & $33(36.3)$ & 58 (63.7) \\
\hline \multicolumn{3}{|c|}{ Use moisturizer after washing } \\
\hline Yes & $32(35.6)$ & $58(64.4)$ \\
\hline No & $21(29.6)$ & $50(70.4)$ \\
\hline \multicolumn{3}{|c|}{ Use moisturizer between toes } \\
\hline Yes & $29(43.3)$ & $38(56.7)$ \\
\hline No & $24(25.5)$ & $70(74.5)$ \\
\hline \multicolumn{3}{|c|}{ Family assistance in washing } \\
\hline Yes & $16(36.4)$ & $28(63.6)$ \\
\hline No & $37(31.6)$ & $80(68.4)$ \\
\hline \multicolumn{3}{|c|}{ Read handouts on foot care } \\
\hline Yes & $13(20.6)$ & $50(79.4)$ \\
\hline No & $40(40.8)$ & $58(59.2)$ \\
\hline \multicolumn{3}{|c|}{$\begin{array}{l}\text { Annual foot examination session by } \\
\text { physician }\end{array}$} \\
\hline Yes & $25(37.3)$ & $42(62.7)$ \\
\hline No & $28(29.8)$ & $66(70.2)$ \\
\hline \multicolumn{3}{|l|}{ Regular physical activity } \\
\hline Yes & $32(29.6)$ & $76(70.4)$ \\
\hline No & $21(39.6)$ & $32(60.4)$ \\
\hline \multicolumn{3}{|l|}{ How many times } \\
\hline$<3$ times per week & $24(38.3)$ & $38(61.7)$ \\
\hline$\geq 3$ times per week & $12(24.4)$ & $34(75.6)$ \\
\hline \multicolumn{3}{|l|}{ Running } \\
\hline Yes & $4(40.00)$ & $6(60.0)$ \\
\hline No & $30(31.6)$ & $65(68.4)$ \\
\hline \multicolumn{3}{|l|}{ Walking } \\
\hline Yes & $29(32.6)$ & $60(67.4)$ \\
\hline No & $5(3 \mid .3)$ & II (68.8) \\
\hline \multicolumn{3}{|l|}{ Jogging } \\
\hline Yes & $4(40.0)$ & $6(60.0)$ \\
\hline No & $30(31.6)$ & $65(68.4)$ \\
\hline \multicolumn{3}{|l|}{ Do you smoke } \\
\hline Yes & $2(50.0)$ & $2(50.0)$ \\
\hline No & $51(32.5)$ & $106(67.5)$ \\
\hline \multicolumn{3}{|l|}{ Footwear } \\
\hline Well fit & $22(34.4)$ & $42(65.6)$ \\
\hline III fit & $31(32.0)$ & $66(68.0)$ \\
\hline
\end{tabular}

$68(63.0 \%)$, respectively. The proportion of taking alcohol among cases and controls was two (3.8\%) and four (3.7\%), respectively (Table 3 ). 


\section{Factors Associated with Diabetic Foot Ulcer}

\section{Bivariate Analysis of Factors Affecting Diabetic Foot} Ulcer

Bivariate analysis was carried out to assess the association of socio-demographic variables, clinical factors, and behavioral factors. Among the socio-demographic variables: occupation, among the clinical factors: kind of treatment of DM taking, peripheral neuropathy, nail problems, and foot deformity, among the behavioral factors: inspecting feet daily, using moisturizer between toes, reading handouts on foot care, and regular physical activity were candidate variables for a multivariable logistic regression model at a $P$-value $<0.25$.

\section{Multivariable Analysis of Factors Affecting Diabetic Foot Ulcer}

The model was checked for fitness using Hosmer and Lemeshow test and the $P$-value was 0.97 .

The multivariable analysis shows that after controlling the possible confounders; occupation, kind of treatment for DM, putting moisturizing cream between toes, daily inspection of foot and peripheral neuropathy were statistically significant with diabetic foot ulcer at $P$-value $<0.05$ (Table 4).

\section{Discussion}

The primary purpose of this study was to assess the determinants of diabetic foot ulcers among adult patients with

Table 4 Factors Associated with Diabetic Foot Ulcer in Diabetic Patients in Addis Ababa City, $2019(\mathrm{n}=161)$

\begin{tabular}{|c|c|c|c|c|c|c|}
\hline Variables & Cases (\%) & Controls (\%) & COR $(95 \% \mathrm{Cl})$ & $P$-value & AOR $(95 \% \mathrm{Cl})$ & $P$-value \\
\hline \multicolumn{7}{|l|}{ Occupation } \\
\hline Employed & $30(40.0)$ & $45(60.0)$ & I & & 1 & \\
\hline Unemployed & $23(26.7)$ & $63(73.3)$ & $0.55(0.28-1.06)$ & 0.08 & $0.35(0.14-0.87)^{* *}$ & 0.03 \\
\hline \multicolumn{7}{|l|}{ Treatment kind of DM } \\
\hline Oral hypoglycemic agents & $15(30.0)$ & $35(70.0)$ & I & & 1 & \\
\hline Insulin & $35(45.5)$ & $42(54.5)$ & $1.94(0.92-4.13)$ & 0.08 & $2.75(1.04-7.23)^{* *}$ & 0.04 \\
\hline Both & $3(8.8)$ & 31 (9I.2) & $0.23(0.06-0.85)^{*}$ & 0.03 & $0.11(0.02-0.57)^{* *}$ & 0.01 \\
\hline \multicolumn{7}{|l|}{ Peripheral neuropathy } \\
\hline Yes & $23(54.8)$ & $19(45.2)$ & $4.18(2.01-8.70)^{*}$ & 0.00 & $7.56(2.82-20.24)^{* *}$ & 0.00 \\
\hline No & $30(25.2)$ & $89(74.8)$ & I & & I & \\
\hline \multicolumn{7}{|l|}{ Inspect your feet daily } \\
\hline Yes & $23(21.9)$ & $82(78.1)$ & I & & I & \\
\hline No & $30(53.6)$ & $26(46.4)$ & $4.11(2.04-8.28)^{*}$ & 0.00 & $5.6 \mathrm{I}(2.24-14.05)^{* *}$ & 0.00 \\
\hline \multicolumn{7}{|l|}{ Putting moisturizer between your toes } \\
\hline Yes & $29(43.3)$ & $38(56.7)$ & $2.23(1.14-4.35)^{*}$ & 0.02 & $3.35(1.35-8.32)^{* *}$ & 0.01 \\
\hline No & $24(25.5)$ & $70(74.5)$ & I & & 1 & \\
\hline \multicolumn{7}{|l|}{ Reading handout on foot care } \\
\hline Yes & I3 (20.6) & $50(79.4)$ & I & & 1 & \\
\hline No & $40(40.8)$ & $58(59.2)$ & $2.65(\mathrm{I} .28-5.5 \mathrm{I})^{*}$ & 0.01 & $1.36(0.53-3.52)$ & 0.52 \\
\hline \multicolumn{7}{|l|}{ Regular physical activity } \\
\hline Yes & $32(29.6)$ & $76(70.4)$ & I & & I & \\
\hline No & $21(39.6)$ & $32(60.4)$ & $1.56(0.78-3.10)$ & 0.21 & $1.52(0.58-4.02)$ & 0.40 \\
\hline \multicolumn{7}{|l|}{ Nail problems } \\
\hline Nail deformity & $14(53.8)$ & $12(46.2)$ & $2.87(1.22-6.76)^{*}$ & 0.02 & $2.61(0.86-7.96)$ & 0.09 \\
\hline No nail problem & $39(28.9)$ & $96(71.1)$ & 1 & & 1 & \\
\hline \multicolumn{7}{|l|}{ Foot deformity } \\
\hline Yes & $7(53.8)$ & $6(46.2)$ & $2.59(0.82-8.13)$ & 0.10 & $2.89(0.55-15.28)$ & 0.21 \\
\hline No & $46(31.1)$ & $102(68.9)$ & I & & 1 & \\
\hline
\end{tabular}

Notes: I = reference, $*$ variables with $P$-value $<0.05$ in bivariate analysis and $* *$ variables that show a significant association in multivariable logistic regression analysis at $P$-value $<0.05$.

Abbreviations: $\mathrm{COR}$, crude odds ratio; $\mathrm{AOR}$, adjusted odds ratio; $\mathrm{Cl}$, confidence interval. 
diabetes. The identified determinants were: occupation, kind of treatment of DM, putting moisturizing cream between toes, daily inspection of foot, and peripheral neuropathy.

In this study, the risk of developing diabetic foot ulcers among employed patients with diabetes was $65 \%$ less likely to occur compared to patients with diabetes who were unemployed. This finding is similar to the crosssectional study done in Arbamich Hospital, Ethiopia, that states, patients with diabetes who were farmers were 6.54times more likely to develop DFU than employed. ${ }^{7}$ But this finding is inconsistent with a cross-sectional study conducted at the University of Gondar Referral Hospital, Ethiopia, that showed occupation was not significantly associated with DFU. ${ }^{8}$ The possible reason for this discrepancy could be due to differences in the occupation status of the participants. This is as those who are employed can afford things that help in the prevention of diabetic foot ulcers.

In this study, patients with diabetes taking insulin alone were 2.75-times more likely to develop a diabetic foot ulcer compared to patients with diabetes taking oral hypoglycemic agents. This finding is consistent with research findings conducted in: Iran, with a prospective cohort study that reveals patients with diabetes taking insulin alone were 5.78-times more likely to develop diabetic foot ulcer compared to patients with diabetes taking oral hypoglycemic agents, ${ }^{27}$ Eastern Indonesia, with a case control study that states patients with diabetes taking insulin were 9.37-times more at risk to develop diabetic foot ulcer compared to patients with diabetes taking oral hypoglycemic agents. ${ }^{18}$ This finding suggests that the more uncontrolled the diabetes, the more risk for diabetic foot ulcer. This is because insulin can be given for diabetes mellitus that cannot be controlled with oral hypoglycemic agents, irrespective of the type of diabetes mellitus. ${ }^{28}$

But this is inconsistent with studies conducted in: Saudi Arabia, with a cross-sectional study that states that taking insulin was not a significant risk factor for the development of DFU, ${ }^{16}$ Malaysia, with a case-control study that showed insulin treatment was not a significant determinant of DFU, ${ }^{29}$ and with a cross-sectional study conducted in University of Gondar Referral Hospital, Ethiopia, that showed taking insulin was not significantly associated with DFU. ${ }^{8}$ The possible reason for this discrepancy could be due to differences in the degree of controlling of the diabetes among the study participants.
In this study, patients with diabetes taking combined medication (insulin and oral hypoglycemic agents) were $89 \%$ less likely to develop diabetic foot ulcers compared to patients with diabetes taking oral hypoglycemic agents. This contradicts with research findings conducted in: Iraq, with a cross-sectional study that showed that using a combination of insulin and oral antidiabetic agents were significantly associated with the development of DFUs ${ }^{30}$ Pakistan, with a cross-sectional study that states that a combination of both insulin and oral hypoglycemic agents was strongly associated with the development of diabetic foot ulcers, ${ }^{19}$ Malaysia, with a case-control study that showed combination of both insulin and oral hypoglycemic agents were not significantly associated with DFU, ${ }^{29}$ and Eastern Indonesia, with a case control study that states taking both insulin and oral hypoglycemic agents were not significantly associated with DFU. ${ }^{18}$ The possible reason for this discrepancy could be due to differences in condition of the diabetes mellitus among the study participants. Since combined medication is given for diabetes mellitus that cannot be controlled by either injection or oral hypoglycemic agents.

In this study, patients with diabetes who have peripheral neuropathy were 7.56-times more at risk to develop diabetic foot ulcers than patients with diabetes without peripheral neuropathy. This finding is consistent with the studies conducted in: Australia, with a cross-sectional study, that reveals patients with diabetes with peripheral neuropathy were 1.77 -times more at risk to develop diabetic foot ulcer than patients with diabetes without peripheral neuropathy, ${ }^{31}$ Iran, with a prospective cohort study that reveals patients with diabetes with distal neuropathy were 3.37-times more at risk to develop diabetic foot ulcers than patients with diabetes without neuropathy, ${ }^{27}$ Pakistan, with a cross-sectional study which states that development of diabetic foot ulcer was more strongly associated with patients with diabetes with neuropathy than patients with diabetes without neuropathy, ${ }^{19}$ and the University of Gondar Referral Hospital, Ethiopia, with a cross-sectional study that reveals patients with diabetes who have neuropathy were 21.76-times more at risk to develop DFU than patients with diabetes who have no neuropathy. ${ }^{8}$ These findings imply that diabetic foot ulcer is inevitable in patients with diabetes with peripheral neuropathy. This is because patients with neuropathy could sustain minor trauma without being aware of the injury until it worsens. It had been suggested that this condition 
can be prevented by wearing proper footwear, maintaining hygiene, and performing daily physical examination. ${ }^{4}$

But this is inconsistent to the studies conducted in: Saudi Arabia, with a cross-sectional study that states neuropathy was not significantly associated with the development of diabetic foot ulcer, ${ }^{15}$ and Arbaminch Hospital, Ethiopia, with a cross-sectional study design which states that neuropathy was not significantly associated with the development of diabetic foot ulcer. ${ }^{7}$ The possible reason for this discrepancy could be due to differences in the duration of diabetes mellitus that the patient has had. The longer duration of diabetes mellitus that the patients have, the more risk of developing a diabetic foot ulcer.

In this study, patients with diabetes who did not inspect their feet daily were 5.61-times more at risk to develop diabetic foot ulcers than patients with diabetes who inspected their feet daily. This is consistent with the case control study conducted in Eastern Indonesia that states that patients with diabetes who inspect their feet were $64 \%$ less at risk to develop diabetic foot ulcer than patients with diabetes who did not inspect their feet daily. ${ }^{18}$ And with the International Working Group on the Diabetic Foot (IWGDF) guideline, which states that at risk patients with diabetes should inspect their feet daily. ${ }^{32}$ These findings imply that daily feet inspection is important for preventing diabetic foot ulcers.

But this is inconsistent with a cross-sectional study conducted in Iraq, where daily foot inspection was not significantly associated with the development of diabetic foot ulcer. ${ }^{30}$ The possible reason for this discrepancy could be due to differences in participants' behavior in inspecting their feet.

In this study, patients with diabetes who use moisturizing cream between their toes were 3.35-times more likely to develop diabetic foot ulcers compared to patients with diabetes who did not use moisturizing cream between their toes. Though no studies show the association of putting cream between toes and diabetic foot ulcer, this finding is consistent with the guideline of Diabetes Foot: Risk Assessment Education Program Participant's Package which states "Do not put cream between the toes". ${ }^{33}$

\section{Limitations}

The retrospective nature of collecting information about some of the variables is prone to recall bias.

It was difficult to get laboratory records of the biologic factors that were taken before the occurrence of the outcome of interest.

\section{Conclusions and Recommendations}

This research showed that taking insulin alone, peripheral neuropathy, not inspecting feet daily, and putting moisturizing cream between toes were positively associated with DFU. Whereas employed and taking both insulin and oral hypoglycemic agents were negatively associated with DFU. It will be beneficial if diabetic patients inspect their feet daily and do not put moisturizing cream between their toes. A prospective cohort study is encouraged to establish the temporal relationship of biologic factors with diabetic foot ulcer.

\section{Data Sharing Statement}

The datasets used and analyzed during this study are available from the corresponding author on reasonable request.

This manuscript's thesis was uploaded to Addis Ababa University Electronic Thesis Library, Adult Health Nursing tract based on an author's permission for academic purposes and available online at http://213.55.95.56/bitstream/handle/ $123456789 / 21435 /$ Guesh Teklu.pdf? sequence $=$ 1\&isAllowed=y http://213.55.95.56/handle/123456789/ 21435). ${ }^{34}$

\section{Acknowledgments}

Our gratitude goes to Addis Ababa University, College of Health Sciences, School of Nursing and Midwifery for its financial support. Our recognition also goes to data collectors, supervisors, workers at diabetic clinic and authorities of Tikur Anbessa Specialized Hospital who were facilitating the data collection. Finally, we would like to thank the study participants who were willing to take part in this study.

\section{Disclosure}

Milete Gebrehiwot Hagos reports [...] and no other potential conflicts of interest for this work. The other authors declare that they have no competing interests for this work.

\section{References}

1. Suzanne CBG, Janice L, Kerry H. BRUNNER \& SUDDARTH'S Textbook of Medical - Surgical Nursing. Wolters Kluwer Health/ Lippincott Williams \& Wilkins; 2010:1197-1236.

2. Armstrong DG, Boulton AJ, Bus SA. Diabetic foot ulcers and their recurrence. $N$ Engl J Med. 2017;376(24):2367-2375. doi:10.1056/ NEJMra1615439

3. Neto AM, Zantut-Wittmann DE, Fernandes TD, Nery M, Parisi MCR. Risk factors for ulceration and amputation in diabetic foot: study in a cohort of 496 patients. Endocrine. 2013;44(1):119-124. doi:10.1007/ s12020-012-9829-2 
4. Bus SA, Lavery LA, Monteiro-Soares M, et al. Guidelines on the prevention of foot ulcers in persons with diabetes (IWGDF 2019 update). Diabetes Metab Res Rev. 2020;36(S1):e3269.

5. Zhang P, Lu J, Jing Y, Tang S, Zhu D, Bi Y. Global epidemiology of diabetic foot ulceration: a systematic review and meta-analysis. Ann Med. 2017;49(2):106-116. doi:10.1080/07853890.2016.1231932

6. Almobarak AO, Awadalla H, Osman M, Ahmed MH. Prevalence of diabetic foot ulceration and associated risk factors: an old and still major public health problem in Khartoum, Sudan? Ann Transl Med. 2017;5(17):340. doi:10.21037/atm.2017.07.01

7. Deribe B, Woldemichael K, Nemera G. Prevalence and factors influencing diabetic foot ulcer among diabetic patients attending Arbaminch Hospital, South Ethiopia. J Diabetes Metab. 2014;5 (1):1-7. doi:10.4172/2155-6156.1000322

8. Mariam TG, Alemayehu A, Tesfaye E, et al. Prevalence of diabetic foot ulcer and associated factors among adult diabetic patients who attend the diabetic follow-up clinic at the university of gondar referral hospital, North West Ethiopia, 2016: institutional-based cross-sectional study. J Diabetes Res. 2017;2017:1-8. doi:10.1155/2017/2879249

9. Gebrekirstos K, Solomon K, Fantahun A. Prevalence and factors associated with diabetic foot ulcer among adult patients in ayder referral hospital diabetic clinic mekelle, North Ethiopia, 2013. $J$ Diabetes Metab. 2015;6(8).

10. Abejew AA, Belay AZ, Kerie MW. Diabetic complications among adult diabetic patients of a tertiary hospital in northeast Ethiopia. Adv Public Health. 2015;2015:1-7. doi:10.1155/2015/290920

11. International Diabetes Federation. IDF Diabetes Atlas. eighth ed. 2017.

12. İçer M, Durgun HM. Factors affecting amputations in patients with diabetic foot ulcer referring to the emergency units. Dicle Tip Derg. 2017;44(1):91-98. doi:10.5798/dicletip.298615

13. Al-Rubeaan K, Almashouq MK, Youssef AM, et al. All-cause mortality among diabetic foot patients and related risk factors in Saudi Arabia. PLoS One. 2017;12(11).

14. Walsh J, Hoffstad O, Sullivan M, Margolis D. Association of diabetic foot ulcer and death in a population-based cohort from the United Kingdom. Diabet Med. 2016;33(11):1493-1498. doi:10.1111/dme.13054

15. Jeong E-G, Cho SS, Lee S-H, et al. Depth and combined infection is important predictor of lower extremity amputations in hospitalized diabetic foot ulcer patients. Korean J Intern Med. 2018;33(5):952. doi:10.3904/kjim.2016.165

16. Al-Rubeaan K, Al Derwish M, Ouizi S, et al. Diabetic foot complications and their risk factors from a large retrospective cohort study. PLoS One. 2015;10(5):e0124446. doi:10.1371/journal.pone.0124446

17. Waaijman R, de Haart M, Arts ML, et al. Risk factors for plantar foot ulcer recurrence in neuropathic diabetic patients. Diabetes Care. 2014;37(6):1697-1705. doi:10.2337/dc13-2470

18. Yusuf S, Okuwa M, Irwan M, et al. Prevalence and risk factor of diabetic foot ulcers in a regional hospital, eastern Indonesia. Open J Nurs. 2016;6(1):1-10. doi:10.4236/ojn.2016.61001

19. Khan MIH, Azhar U, Zubair F, Khan ZA. Can we link foot ulcer with risk factors in diabetics? A study in a tertiary care hospital. Pak J Med Sci. 2018;34(6):1375. doi:10.12669/pjms.346.16199
20. Tshitenge S, Ganiyu A, Mbuka D, Shama JM. The diabetic foot risks profile in selebi phikwe government hospital, botswana. Afr J Prim Health Care Fam Med. 2014;6(1):1-5. doi:10.4102/phcfm.v6i1.610

21. Sibbald RG, Ostrow B, Lowe J, et al. Screening for the high-risk diabetic foot: a 60-second tool (2012)(C: diabetes. Wound Heal South Afr. 2012;5(2):72-82.

22. Woodbury MG, Sibbald RG, Ostrow B, Persaud R, Lowe JM. Tool for rapid \& easy identification of high risk diabetic foot: validation \& clinical pilot of the simplified 60 second diabetic foot screening tool. PLoS One. 2015;10(6):e0125578. doi:10.1371/journal.pone.0125578

23. Bower VM, Hobbs M. Validation of the basic foot screening checklist: a population screening tool for identifying foot ulcer risk in people with diabetes mellitus. J Am Podiatr Med Assoc. 2009;99 (4):339-347. doi:10.7547/0980339

24. Persaud R, Coutts PM, Brandon A, Verma L, Elliott JA, Sibbald RG. Validation of the healthy foot screen: a novel assessment tool for common clinical abnormalities. Adv Skin Wound Care. 2018;31 (4):154-162. doi:10.1097/01.ASW.0000530686.16243.d5

25. Bursac Z, Gauss CH, Williams DK, Hosmer DW. Purposeful selection of variables in logistic regression. Source Code Biol Med. 2008;3 (1):17. doi:10.1186/1751-0473-3-17

26. World Health Organization. Global Database on Body Mass Index. 2006.

27. Yazdanpanah L, Shahbazian H, Nazari I, et al. Incidence and risk factors of diabetic foot ulcer: a population-based diabetic foot cohort (ADFC study) - two-year follow-up study. Int $J$ Endocrinol. 2018;2018:1-9. doi:10.1155/2018/7631659

28. Food, Medicine and Healthcare Administration and Control Authority of Ethiopia. Standard Treatment Guidelines for General Hospitals. Third ed. 2014; 73.

29. Fauzi AA, Chung TY, Latif LA. Risk factors of diabetic foot Charcot arthropathy: a case-control study at a Malaysian tertiary care centre. Singapore Med J. 2016;57(4):198. doi:10.11622/smedj.2016074

30. Mohammed SI, Mikhael EM, Ahmed FT, Al-Tukmagi HF, Jasim AL. Risk factors for occurrence and recurrence of diabetic foot ulcers among Iraqi diabetic patients. Diabet Foot Ankle. 2016;7(1):29605. doi:10.3402/dfa.v7.29605

31. Jia L, Parker CN, Parker TJ, et al. Incidence and risk factors for developing infection in patients presenting with uninfected diabetic foot ulcers. PLoS One. 2017;12(5):e0177916. doi:10.1371/journal. pone.0177916

32. Bus S, Van Netten J, Lavery L, et al. IWGDF guidance on the prevention of foot ulcers in at-risk patients with diabetes. Diabetes Metab Res Rev. 2016;32:16-24. doi:10.1002/dmrr.2696

33. Moyer A, Delmas L, Little M. et al. Diabetes Foot: Risk Assessment Education Program Participant's Package. 2004.

34. Teklu G. Determinants of Diabetic Foot Ulcer Among Adult Patients with Diabetes Attending the Diabetic Clinic in Tikur Anbessa Specialized Hospital, Addis Ababa. Ethiopia: Unmatched case - control study; 2019.

Diabetes, Metabolic Syndrome and Obesity: Targets and Therapy

Dovepress

\section{Publish your work in this journal}

Diabetes, Metabolic Syndrome and Obesity: Targets and Therapy is an international, peer-reviewed open-access journal committed to the rapid publication of the latest laboratory and clinical findings in the fields of diabetes, metabolic syndrome and obesity research. Original research, review, case reports, hypothesis formation, expert opinion and commentaries are all considered for publication. The manuscript management system is completely online and includes a very quick and fair peer-review system, which is all easy to use. Visit http://www.dovepress.com/testimonials.php to read real quotes from published authors. 